\title{
RANDOMIZED CONTROLLED TRIAL OF LIMITED FASCIECTOMY WITH INJECTION OF ADIPOSE GRAFT FOR DUPUYTREN'S DISEASE
}

\author{
ESTUDO COMPARATIVO RANDOMIZADO DE ENXERTO \\ DE GORDURA PARA A DOENÇA DE DUPUYTREN
}

\author{
marina tommasini C. Sambuy ${ }^{1}$ (i), Hugo a. Nakamoto ${ }^{1}$ (i), Raul Bolliger Neto ${ }^{1}$ (i), Rames Mattar JR. ${ }^{1}$ (i), \\ MARCELO R. REZENDE ${ }^{1}$ (1), TENG HSIANG WeI ${ }^{1}$ (1)
}

1. Universidade de São Paulo, Medical School, Hospital das Clínicas, Institute of Orthopedics and Traumatology, São Paulo, SP, Brazil.

\section{ABSTRACT}

Objective: Dupuytren's disease is a genetic disorder related to the proliferation of myofibroblasts. The pluripotent property of stem cells present in adipose tissue inhibits myofibroblast proliferation. Our study sought to evaluate the effect of stem cell-rich fat grafts in patients that underwent limited fasciectomy. Methods: We studied 45 patients, in a single-blind, prospective, randomized clinical trial. All patients underwent limited fasciectomy. In one group, fat graft was injected. Results: The total passive extension deficit results did not exhibit a significant difference. Fat group exhibited worse functional score at 6 months and 1 year postoperatively, such as higher complication rates (43\%), when compared with control group (8\%), and more pain at 6 weeks follow-up. Conclusion: Fat grafting associated with limited fasciectomy promotes worse functional results compared to conventional limited fasciectomy in the short term. However, long-term results and recurrence rates should be further assessed. Level of Evidence II, Prospective comparative study.

Keywords: Dupuytren Contracture. Adipose Tissue. Fasciectomy. Stem Cells. Randomized Controlled Trial. Clinical Trial.

\section{RESUMO}

Objetivo: A moléstia de Dupuytren (MD) está associada a um distúrbio genético relacionado à proliferação de miofibroblastos. Acredita-se que a propriedade totipotente das células-tronco, presentes no tecido adiposo, seria capaz de inibir a formação dos miofibroblastos. O objetivo deste estudo foi avaliar o efeito do enxerto de gordura, rico em células-tronco, nos pacientes com MD, submetidos à fasciectomia parcial. Métodos: Estudamos 45 pacientes, em um ensaio clínico prospectivo, randomizado e cego. No grupo-controle, era realizada apenas a fasciectomia parcial. No grupo com gordura, era realizada a fasciectomia parcial e injetado o enxerto de gordura. Os desfechos foram avaliados pelo Déficit de Extensão Passiva Total (DEPT) e escore funcional Brief Michigan Hand Questionnaire (BMHQ). Resultados: Os resultados do déficit de extensão passiva total não apresentaram diferença significativa. O grupo com gordura apresentou pior escore funcional após 6 meses e 1 ano, como maiores taxas de complicações (43\%) em comparação ao grupo controle (8\%) e mais dor com 6 semanas de seguimento. Conclusão: O uso de enxerto de gordura associado à fasciectomia parcial promove piores resultados funcionais em comparação com a fasciectomia parcial convencional, a curto prazo. No entanto, a recidiva e os resultados a longo prazo devem ser avaliados. Nível de Evidência II, Estudo prospectivo comparativo.

Descritores: Contratura de Dupuytren. Tecido Adiposo. Fasciotomia. Células-Tronco. Ensaio Clínico Controlado Aleatório. Ensaio Clínico.

Citation: Sambuy MTC, Nakamoto HA, Bolliger Neto R, Mattar R Jr., Rezende MR, Wei TH. Randomized controlled trial of limited fasciectomy with injection of adipose graft for Dupuytren's Disease. Acta Ortop Bras. [online]. 2020;28(4):159-64. Available from URL: http://www.scielo.br/aob.

\section{INTRODUCTION}

Dupuytren's disease (DD) is a progressive chronic fibroproliferative disease characterized by contractures in flexion of the fingers. ${ }^{1}$ Various techniques such as percutaneous fasciotomy, open limited fasciotomy, dermofasciotomy, and collagenase clostridium histolyticum applications have been described for treating DD..$^{2-5}$
Growing evidence suggests that fat-mediated autologous grafting can treat fibrosis and scarring contractures throughout the body. ${ }^{6}$ This action is related to the ability of stem cells to inhibit the proliferation of contractile myofibroblasts, and these effects are mediated by soluble factors influenced by cellular. ${ }^{6-8}$

Hovius et al. ${ }^{9}$ were among the first to associate fat grafting with percutaneous fasciotomy in their Extensive Percutaneous

All authors declare no potential conflict of interest related to this article.

The study was conducted at Universidade de São Paulo, Medical School, Hospital das Clínicas, Institute of Orthopedics and Traumatology.

Correspondence: Marina Tommasini Carrara de Sambuy. Rua Dona Adma Jafet, 74, cj 144, São Paulo, SP, Brazil, 01308050. marinacarrara@hotmail.com 
Aponeurotomy and Lipografting (PALF) technique. They presented certain cases, in which they performed aponeurotomy in every cord path and then injected the fat graft into the space created between the skin and the sectioned cord, obtaining good results. ${ }^{7,8}$

Considering this scenario, the question arises if fat grafting from autologous lipoaspirate can be beneficial when associated with open limited fasciotomy.

Our study sought to evaluate the functional and goniometry outcomes of patients with DD that underwent open limited fasciotomy using stem cell-rich fat graft and compare these results with those that underwent open limited fasciotomy without the addition of fat graft.

\section{MATERIALS AND METHODS}

Between February 2014 and November 2017, 45 DD patients were studied in a simple, prospective, randomized clinical trial. Patients over 40 years of age, both males and females, with Total Passive Extension Deficit (TPED) greater than 30 degrees in the metacarpophalangeal, proximal interphalangeal and distal interphalangeal joints were included. Patients with previous treatment or those with medical conditions that precluded general anesthesia were excluded. All patients were informed about the study and signed an informed consent form. The Ethics Committee for Analysis of Hospital Research Projects duly approved the study.

\section{Flow of participants}

In total, 100 patients were evaluated for the treatment of DD at the outpatient clinic between February 2014 and November 2017. However, 45 patients were excluded. Of these, 40 had previous surgery and therefore were considered to have a recurrence, and 5 had no clinical conditions to undergo surgery. Before randomization, 5 patients were excluded - two did not return for evaluation, and 3 refused surgery.

A total of 45 patients were included in the study: 24 were randomly assigned to control group and 26 to fat group. During the study, five patients in fat group were excluded - two abandoned follow-up, and 3 did not undergo the minimum follow-up time of 1 year. Thus, 21 patients were included in fat group.

\section{Randomization}

The patients were stratified into four subgroups (I to IV) based on the severity of the disease according to the Tubiana Classification of 1986 (Table 1). Each of the four subgroups were randomized separately to obtain homogeneous groups according to the disease severity. The randomization into two groups was performed by electronic software (Excel for Windows) (Figure 1). In one group (control group), only open limited fasciotomy was performed. In the other group (fat group), limited fasciotomy was performed, and the fat graft was injected at the resected cord site (Figure 1).

\begin{tabular}{|c|c|c|c|c|}
\hline Selection & & Assesse & ligibility & $\begin{array}{l}\text { Did not meet the } \\
\text { inclusion criteria }\end{array}$ \\
\hline Randomization & & Rando & $(n=50)$ & $\begin{array}{l}\text { operated on }(n=3) \\
\text { Did not return to }\end{array}$ \\
\hline & $\sqrt{ }$ & $\vee$ & $\downarrow$ & $\vee$ \\
\hline & Tubiana I & Tubiana II & Tubiana III & Tubiana IV \\
\hline & & & & \\
\hline Homogenization & \begin{tabular}{|ll}
$09 \mathrm{El}$ & $A$
\end{tabular} & 02Ell B & 06EIII A & 05DIV B \\
\hline & $38 \mathrm{El} \quad A$ & 04EII B & 08DIII A & 07EIV A \\
\hline & $31 \mathrm{UI} \quad \mathrm{B}$ & $10 E \|$ & 11EIII B & 16DIV B \\
\hline & $34 \mathrm{DI} \quad \mathrm{B}$ & 17DII A & 12DIII $B$ & 24EIV A \\
\hline
\end{tabular}

Figure 1. Flow diagram detailing group allocation.
Table 1. Preoperative TPED evaluation of Tubiana classification.

\begin{tabular}{c|c|c|c|c}
\hline \multicolumn{4}{|c|}{ Groups } & \multicolumn{2}{c}{ Fat group } \\
\hline Tubiana Stage & \multicolumn{2}{|c|}{ Control group } & N & $\%$ \\
\hline I $\left(0^{\circ}-45^{\circ}\right)$ & 5 & $21 \%$ & 4 & $19 \%$ \\
\hline II $\left(45^{\circ}-90^{\circ}\right)$ & 10 & $42 \%$ & 11 & $52 \%$ \\
\hline III $\left(90^{\circ}-135^{\circ}\right)$ & 8 & $33 \%$ & 4 & $19 \%$ \\
\hline IV $\left(\geq 135^{\circ}\right)$ & 1 & $4 \%$ & 2 & $10 \%$ \\
\hline Total & 24 & $100 \%$ & 21 & $100 \%$ \\
\hline TPED (Total Passive Extension Deficit) = Passive Extension Deficit of MF + IFP + IFD
\end{tabular}

\section{Surgical technique}

Patients were subjected to general anesthesia or regional block and sedation, and a pneumatic tourniquet was placed in the arm. All patients underwent open limited fasciotomy after their inclusion on the same protocol of postoperative rehabilitation by the hand therapy team. The protocol involved early mobilization and splinting in extension during the night for 6 weeks.

\section{Open limited fasciotomy}

A Brunner-type incision was performed, followed by dissection of the subcutaneous tissue and the cord in the palmar region and finger if necessary. The neurovascular bundle was identified and protected, ensuring its preservation throughout the procedure. The cord was sectioned in its palmar origin followed by its resection in the distal direction until the complete extension of the finger (Figure 2). The tourniquet was released, and hemostasis was carefully performed. The skin was then closed with single stitches (Figure 2). At this time, the surgeon was informed of the group to which the patient was allocated (randomization). If the patient belonged to the control group, a bandage dressing was applied, and the procedure was complete (Figure 2). If the patient belonged to the fat group, harvesting and grafting were performed. Thus, the patients in both groups underwent exactly the same operative technique.

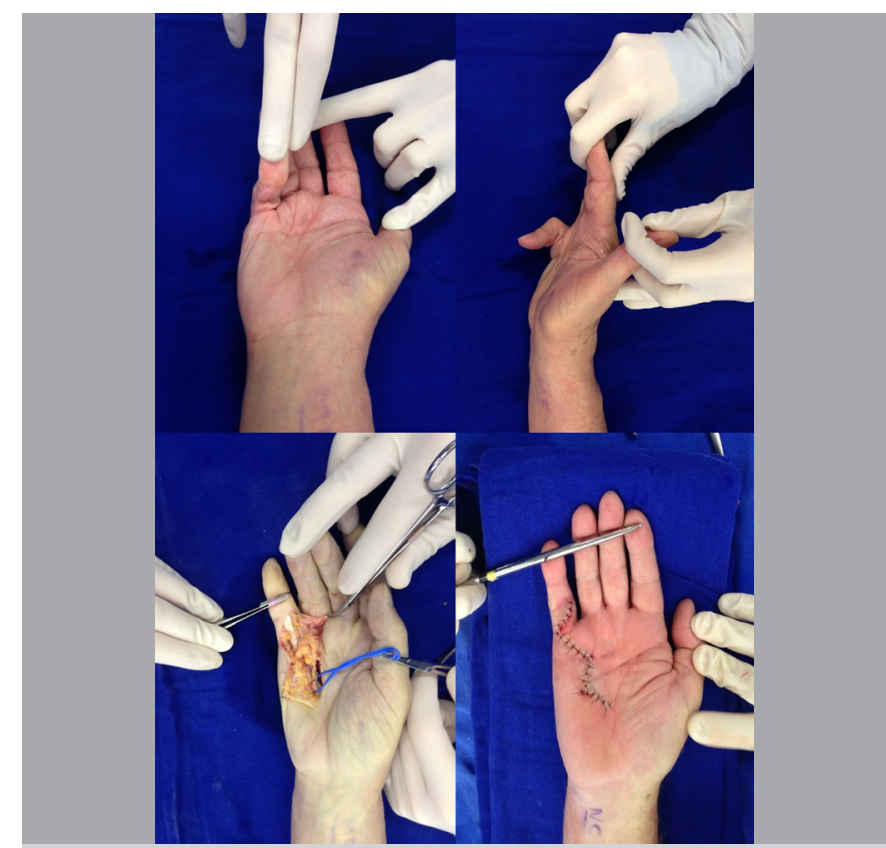

Figure 2. Open limited fasciotomy. (Upper pictures), preoperative clinical aspect demonstrating contracture of the 5th finger, anterior view and profile view; (lower left), intraoperative clinical aspect; (lower right), clinical aspect after skin closure demonstrating complete extension of the finger. 
All patients were night splinted for 6 weeks and ultimately participated in approximately 10 sessions of hand therapy. However, patients that experienced CRPS as complication required a different approach by the hand therapy team.

\section{Harvesting and infiltration of autologous lipoaspirate}

A small 5-mm incision was made in the periumbilical abdominal region according to the classic technique of liposuction with $1.5 \mathrm{~mm}$ thick fine microcannula (Coleman ${ }^{\mathrm{TM}}$ Microcannula). The microcannula aspirator coupled to a $20 \mathrm{ml}$ syringe was introduced into the adipose layer via back-and-forth movements, and the fat was released and aspirated. ${ }^{10,11}$ Lipoaspiration resulted in $10 \mathrm{ml}$ of autologous fat graft. The contents were placed in properly capped syringes and then transported to a specific centrifuge to be processed. The lipoaspirate was processed in the centrifuge for 3 minutes at 3,000 rpm and 756 of $\mathrm{G}$ force. The supernatant was discarded, leaving the viable adipocytes among other components. Five milliliters of purified lipoaspirate were introduced into a sterile syringe and injected through a microcannula between the skin and the deep planes. Lipoaspirate was slowly injected with no pressure as a longitudinal single track of the resected cord, forming a "micro-ribbon" of $1.5 \mathrm{~mm}$, which is consistent with the ideal circumstances for adipocyte survival. ${ }^{12}$ The final dressing was performed with the same type of packing as the control group (Figure 3).

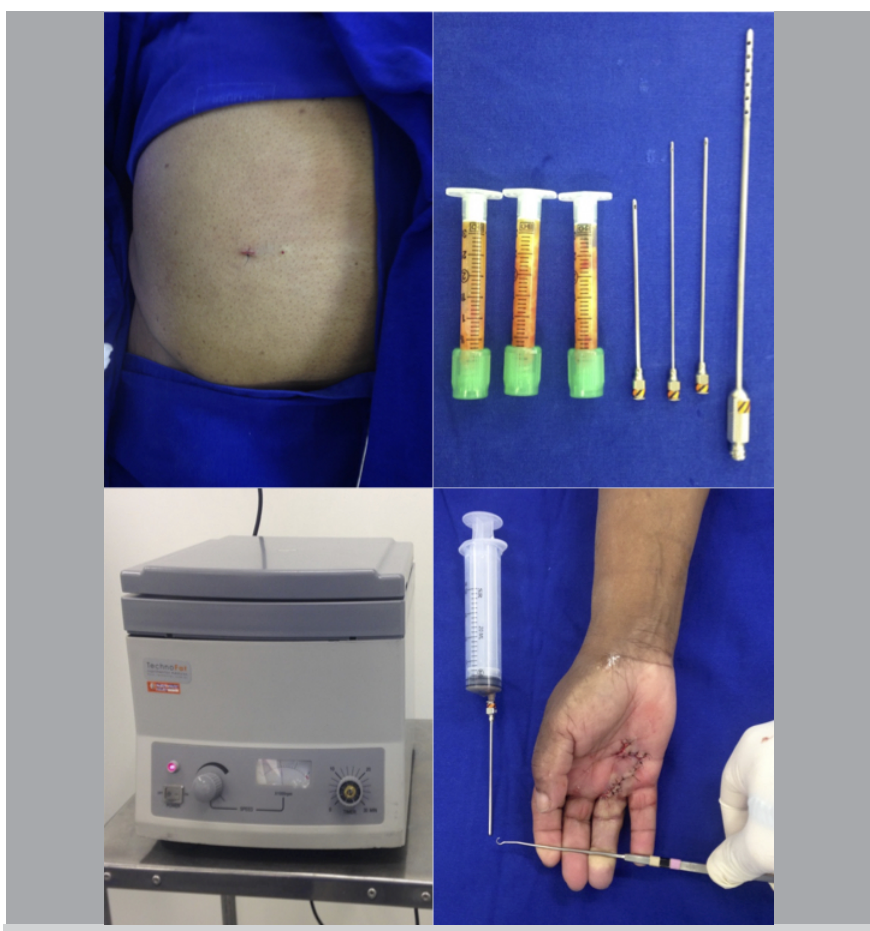

Figure 3. Process of liposuction of fat with thin cannulas. (Upper left), abdomen incision where the liposuction was performed; (upper right), aspirating microcannulas with fat; (bottom left), fat centrifuging; (lower right), fat already injected into the space previously occupied by the cord.

\section{Outcomes and measures}

The outcomes were assessed by TPED, the visual analogue scale (VAS) values (from 0 , no pain up to 10 , worst pain), and the Brief Michigan Hand Questionnaire (BMHQ) functional score, that addresses specifically hand function. ${ }^{13}$

We guaranteed the "blind" evaluation of the results performed by hand therapists in the rehabilitation Department of Hand Therapy, separate from the outpatient clinic. The evaluators assigned to the functional questionnaire and the goniometric measurement were not aware of the group to which the patient belonged. Only the surgeon was aware of this detail. We used the online data storage tool REDCap ${ }^{\circledR}$, which was developed for scientific research and allows the safe storage of information and online filling by different researchers. ${ }^{14}$ Each researcher had a personal login and password, and every change was recorded.

We used only the worst ray measurements of each hand to avoid confounding the data.

\section{Complications}

The collected data regarding possible complications were infection, nerve damage, tendon injury, operative wound dehiscence, hematoma, and CRPS. The medical team performed weekly or biweekly returns in the postoperative period until the skin healed.

\section{Estimated sample calculation}

The primary outcome was TPED of the most contracted finger measured with a goniometer in total passive extension at the 1-year follow-up consult. The considered effect size was a difference of $25 \pm 35$ degrees of the standard deviation based on the first twenty cases that underwent surgery (10 for each group). We selected a sample of 31 cases for each group based on a 0.05 alpha error and a 0.20 beta error.

\section{Statistical analysis}

Baseline data were analyzed to verify if the groups were homogeneous concerning the stratification and randomization process. For analysis of inferential statistics, the Kolmogorov-Smirnov normality test was performed for continuous data to observe the distribution of the sample data. Statistical significance was considered for $p<0.05$. We used the Wilcoxon-Mann-Whitney test, since the data presented a non-parametric distribution, and the chi-square test, for the analysis of complications. Some missing data were imputed on the final table by calculating the percentage of improvement of the group being analyzed given that they were considered as random losses (Missing at Random) of a group that follows the same pattern. Data analysis was performed using SPSS software version 20.0.

\section{RESULTS}

\section{Intrinsic patient variables}

The groups were homogeneous regarding the degree of contracture as evaluated by the Tubiana classification (Table 1).

The patients' ages ranged from 49 to 85 years, with an average age of 66 years (Table 2). No significant difference was noted between the two groups regarding the incidence of comorbidities.

Table 2. Intrinsic patient variables and categorical data

\begin{tabular}{|c|c|c|c|c|c|c|}
\hline \multicolumn{7}{|c|}{ Groups } \\
\hline & & \multicolumn{2}{|c|}{ Control group } & \multicolumn{2}{|c|}{ Fat group } & \multirow{2}{*}{$p$} \\
\hline & & $\mathbf{N}$ & $\%$ & $\mathbf{N}$ & $\%$ & \\
\hline \multirow[t]{3}{*}{ Gender } & Male & 20 & $83 \%$ & 14 & $67 \%$ & \\
\hline & Female & 4 & $17 \%$ & 7 & $33 \%$ & \\
\hline & Total & 24 & $100 \%$ & 21 & $100 \%$ & 0.176 \\
\hline \multirow{3}{*}{$\begin{array}{l}\text { Dominant } \\
\text { side }\end{array}$} & Yes & 13 & $54 \%$ & 7 & $33 \%$ & \\
\hline & No & 11 & $46 \%$ & 14 & $67 \%$ & \\
\hline & Total & 24 & $100 \%$ & 21 & $100 \%$ & 0.212 \\
\hline \multirow{3}{*}{$\begin{array}{l}\text { Presence } \\
\text { of nodules }\end{array}$} & Yes & 23 & $96 \%$ & 19 & $90 \%$ & \\
\hline & No & 1 & $4 \%$ & 2 & $10 \%$ & \\
\hline & Total & 24 & $100 \%$ & 21 & $100 \%$ & 0.592 \\
\hline \multirow{3}{*}{$\begin{array}{c}\text { Presence } \\
\text { of cords }\end{array}$} & Yes & 24 & $100 \%$ & 19 & $90 \%$ & \\
\hline & No & 0 & $0 \%$ & 2 & $10 \%$ & \\
\hline & Total & 24 & $100 \%$ & 21 & $100 \%$ & 0.212 \\
\hline
\end{tabular}




\section{Analysis of outcomes}

\section{Visual analogue pain scale}

We used the median to compare the data between the groups, since the results did not follow the normality curve. The median preoperative VAS score was 2 in the control group and 5 in the fat group with no significant difference $(p=0.616)$. At 6 weeks postoperatively, both groups presented pain relief compared to preoperative values; however, VAS score values in the fat group postoperatively were significantly higher than control group $(p=0.045)$. The patients did not refer to pain in the fat donor site. Comparison of the groups at the 6-month and 1-year follow-up showed no statistically significant differences $(p=0.487, p=0.864$ and $p=0.290$, respectively) (Table 3 ).

Table 3. Evaluation of pain level according to VAS during follow-up.

\begin{tabular}{c|c|c|c|c|c}
\hline & N & Median & Minimum & Maximum & $p$ \\
\hline Pre-Operative & & & & & \\
\hline Control & 24 & 2 & 0 & 9 & 0.616 \\
\hline With fat & 21 & 5 & 0 & 9 & \\
\hline 6 weeks & & & & & \\
\hline Control & 24 & 0 & 0 & 5 & $0.045^{*}$ \\
\hline With fat & 21 & 2 & 0 & 9 & \\
\hline 6 months & & & & & \\
\hline Control & 24 & 0 & 0 & 5 & 0.487 \\
\hline With fat & 21 & 0 & 0 & 9 & \\
\hline 1 year & & & & & \\
\hline Control & 24 & 0 & 0 & 5 & 0.864 \\
\hline With fat & 21 & 0 & 0 & 9 & \\
\hline
\end{tabular}

$\mathrm{N}$ : number of patients; $p$ : level of significance; *: statistical significance $(p<0.05)$.

\section{TPED analysis}

TPED analysis results for the two groups showed no significant difference (Table 4, Figure 4). We assume as recurrence criterion a loss greater than or equal to 30 degrees when compared with postoperative measurements. ${ }^{4}$

Table 4. Results of the measurement of TPED during the follow-up.

\begin{tabular}{|c|c|c|c|c|c|}
\hline & $\mathbf{N}$ & Median & Minimum & Maximum & $p$ \\
\hline \multicolumn{6}{|c|}{ Pre-operative } \\
\hline Control & 24 & 77.50 & 35 & 150 & 0.784 \\
\hline With Fat & 21 & 75.00 & 25 & 155 & \\
\hline \multicolumn{6}{|l|}{6 weeks } \\
\hline Control & 24 & 15.00 & 0 & 55 & 0.198 \\
\hline With Fat & 21 & 25 & 0 & 65 & \\
\hline \multicolumn{6}{|l|}{6 months } \\
\hline Control & 24 & 10.00 & 0 & 45 & 0.101 \\
\hline With Fat & 21 & 15.00 & 0 & 130 & \\
\hline \multicolumn{6}{|l|}{1 year } \\
\hline Control & 24 & 10.00 & 0 & 60 & 0.151 \\
\hline With Fat & 21 & 25.00 & 0 & 135 & \\
\hline
\end{tabular}

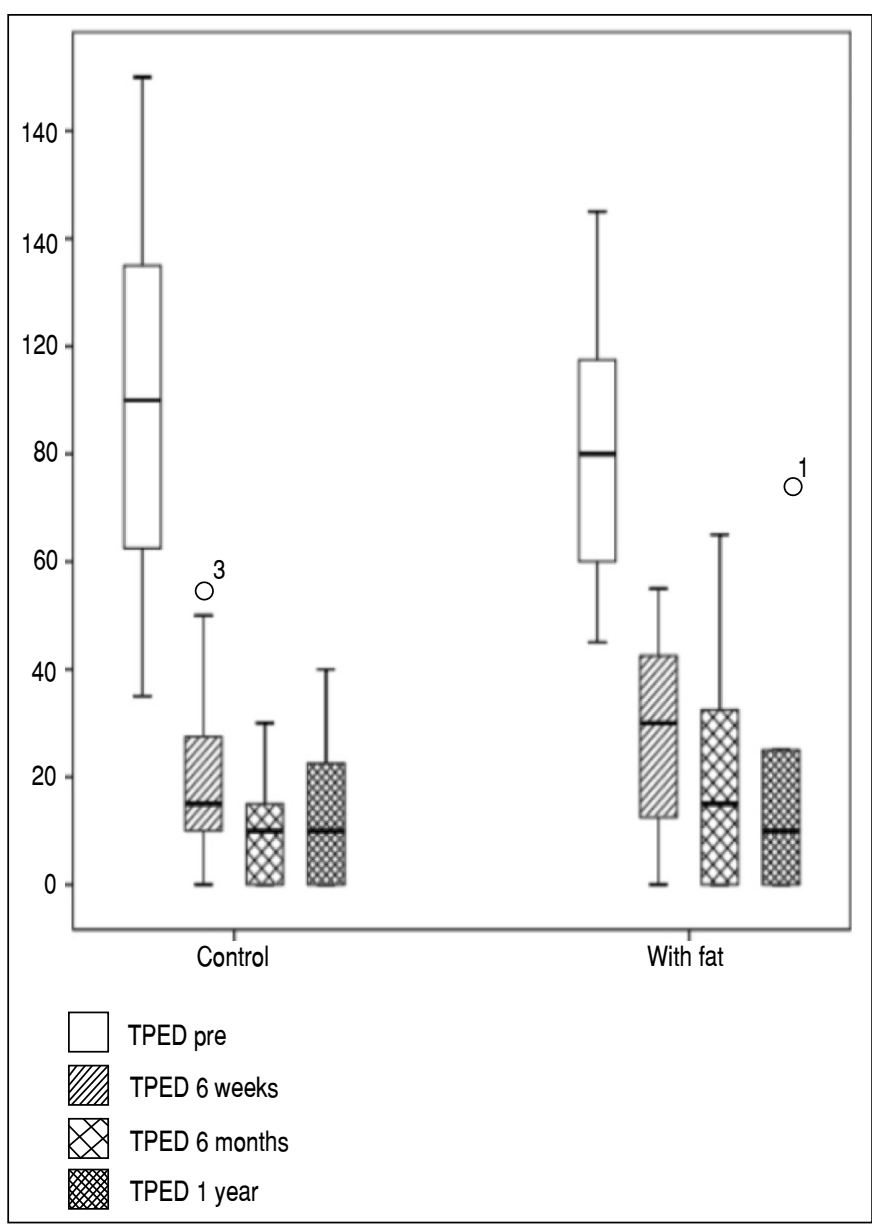

Figure 4. Results of the TPED measurement during the follow-up.

\section{Analysis of the $B M H Q$ score}

The median BMHQ score in the preoperative period was 55.20 in the control group and 60.41 in the fat group, and the result was not statistically significant $(p=0.241)$. At the 6 -month and 1 -year evaluation, significant differences were noted between the groups ( $p=0.040$ and 0.048 , respectively). After 6 months postoperatively, the medians were 92.70 in the control group and 83.33 in the fat group. In comparison, the medians observed at 1-year postoperatively were 91.28 in the control group and 87.50 in the fat group. The results are shown in Table 5 and Figure 5.

Table 5. BMHQ score results during follow-up.

\begin{tabular}{|c|c|c|c|c|c|}
\hline & $\mathbf{N}$ & Median & Minimum & Maximum & $p$ \\
\hline \multicolumn{6}{|c|}{ Pre-operative } \\
\hline Control & 24 & 55.20 & 11.13 & 89.58 & 0.241 \\
\hline With Fat & 21 & 60.41 & 27.08 & 89.58 & \\
\hline \multicolumn{6}{|l|}{6 weeks } \\
\hline Control & 24 & 79.16 & 43.75 & 97.91 & 0.121 \\
\hline With Fat & 21 & 23.66 & 22.72 & 100.00 & \\
\hline \multicolumn{6}{|l|}{6 months } \\
\hline Control & 24 & 92.70 & 50.00 & 100.00 & $0.040^{*}$ \\
\hline With Fat & 21 & 83.33 & 25.00 & 100.00 & \\
\hline \multicolumn{6}{|l|}{1 year } \\
\hline Control & 24 & 91.28 & 64.58 & 100.00 & $0.047^{\star}$ \\
\hline With Fat & 21 & 87.50 & 43.75 & 96.03 & \\
\hline
\end{tabular}




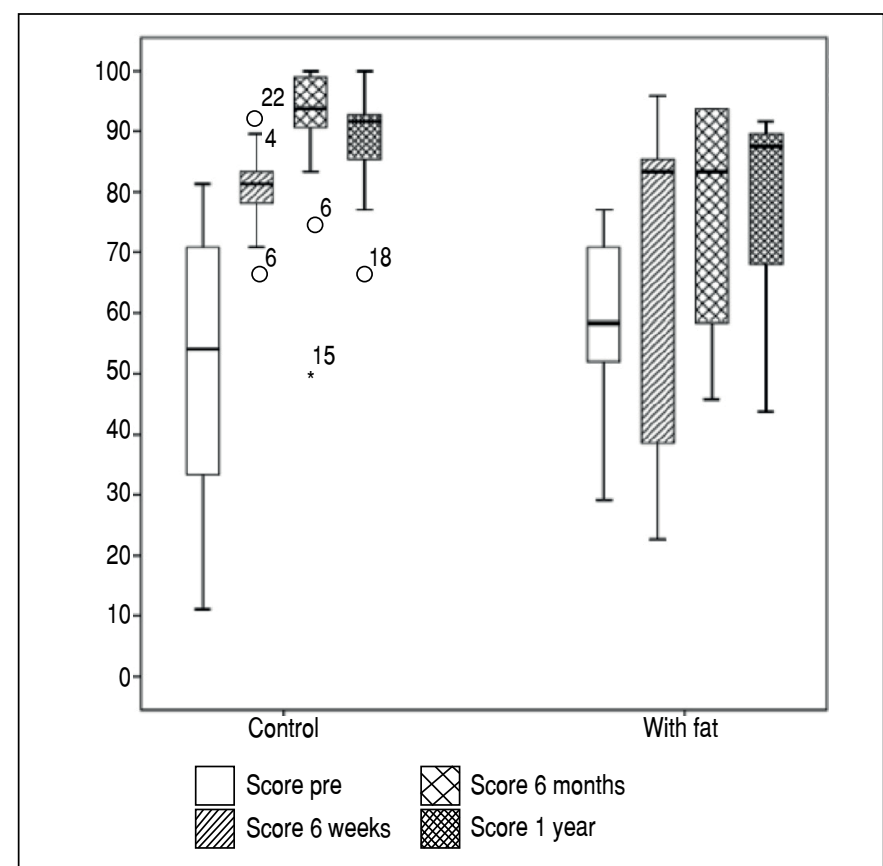

Figure 5. BMHQ score results during follow-up.

\section{Complications}

Complications were observed in 11 patients. Two patients had more than one occurrence. One patient presented infection and dehiscence of the surgical wound, and the other had digital nerve injury and CRPS. The following complications were observed: one case of infection, one case of hematoma, one case of hypertrophic scar, three cases of dehiscence, and five cases of CRPS (Table 6, Figure 6).

Table 6. Postoperative complications during follow-up.

\begin{tabular}{c|c|c|c|c|c}
\hline \multicolumn{7}{c}{ Groups } \\
\hline & \multicolumn{2}{|c|}{ Control group } & \multicolumn{2}{c}{ Fat group } & \multirow{2}{*}{$\boldsymbol{p}$} \\
\hline Intercurrences & $\mathbf{N}$ & $\%$ & $\mathbf{N}$ & $\%$ & \\
\hline Infection & 0 & $0 \%$ & 1 & $5 \%$ & \\
\hline Dehiscence & 1 & $4 \%$ & 2 & $10 \%$ & \\
\hline Hematoma & 0 & $0 \%$ & 1 & $5 \%$ & \\
\hline CRPS & 1 & $4 \%$ & 4 & $19 \%$ & \\
\hline Hypertrophic scar & 0 & $0 \%$ & 1 & $5 \%$ & \\
\hline Total & 2 & $8 \%$ & 9 & $43 \%$ & 0.019 \\
\hline
\end{tabular}

$\mathrm{N}$ : number of patients; $p$ : level of significance.

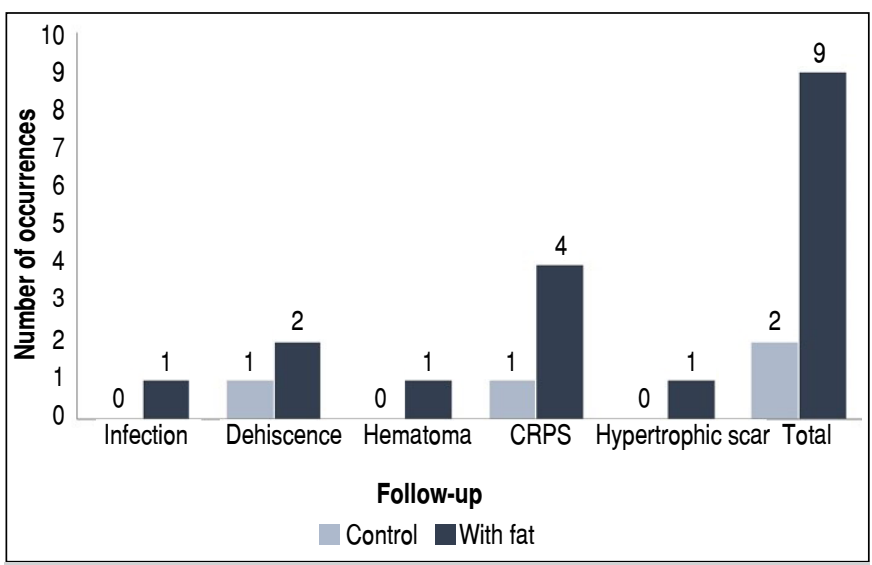

Figure 6. Postoperative complications during follow-up
Control group had one case of dehiscence and one of CRPS. Fat group had one case of infection, one case of hematoma, one case of hypertrophic scar, two cases of dehiscence, and four cases of CRPS. Of the patients with CRPS, four were type I or "classic" CRPS and one was type II, which involves identifiable peripheral nerve injury (causalgia) due to intraoperative digital nerve injury

\section{DISCUSSION}

The benefits of adipose tissue rich in stem cells in the treatment of cicatricial contractures are described in several articles. ${ }^{6-9,15}$ These benefits are related to the inhibition of myofibroblasts and the restoration of subcutaneous atrophy by fat graft. ${ }^{16}$

However, there is no evidence of these benefits in the treatment of DD. Studies have assessed fat grafting in the treatment of DD after an extensive percutaneous aponeurotomy and ultimately demonstrated benefits with the association of fat graft. ${ }^{7-9}$

Kan et al. $^{16}$ were the first to compare the technique of extensive percutaneous aponeurotomy followed by fat filling with the conventional technique of open limited fasciotomy. The authors obtained similar results among the techniques, but reduced complication and faster return to work were noted in the group in which fat was used. ${ }^{16}$ However, no randomized clinical trials that use one surgical technique for all of the patients and associate fat in a group to evaluate its action alone have been performed prior to this study. We consider that the use of fat grafting is essential and should be treated as a single variable; thus, all the patients underwent a standard surgical procedure in our study.

To specifically analyze the effect of fat grafting, we compared two groups (with and without fat) using the conventional technique of open limited fasciotomy.

Our findings showed statistically significant differences between the groups. We observed worse results in the functional BMHQ score at 6 months and 1 year postoperatively in the fat group $(p=0.040$ and $p=0.047$, respectively) (Table 5, Figure 5).

The fat group had a significant increase in pain on the VAS scale at 6 weeks postoperatively [median 2 versus 0 in the control group $(p=0.045)]$.

We also observed 9 cases (43\%) of complications in the fat group and $2(8 \%)$ in the control group; a statistically significant difference was observed between the groups by the Chi-square test ( $p=0.019)$. Among them, five cases were CRPS: four in the fat group (19\%) and 1 in the control group (4\%). Fat group had one case of nerve injury that may influence the results. We chose not to exclude it due to the importance of showing all negative results. The incidence of complications following the technique of open limited fasciotomy is typically increased when compared with percutaneous techniques, especially for CRPS, ranging from $1.3 \%$ to $13 \% .^{5,17}$ However, increased rates were noted in the fat group: a total of $43 \%$ with complications and $19 \%$ of these with CRPS. Five patients belonging to the fat group were excluded during the study. Three did not return for the final evaluation, one presented CRPS and wanted to leave the study, and the fifth did not return. These cases would possibly contribute to the worsening of the fat group results. The remaining patients did not complete the minimum follow-up time of 1 year.

We believe that the decrease in the BMHQ functional score and the increase in pain at 6 weeks postoperatively in the fat group are due to the high complication rates in this group, in which some individuals shifted the median lower. The worst results found in the fat group differed from the results of previous studies that used fat grafts in the treatment of DD.--9,16,18 However, those studies used different surgical techniques between the groups, namely, extensive percutaneous aponeurotomy and fat grafting, and did not used the same technique for the control group. Thus, the reported benefits 
could not be exclusively attributed to the action of fat or simply the technique of extensive percutaneous aponeurotomy.

Grafting fat into a larger space (fasciotomy) may compromise neovascularization of part of the fat grafted. However, tissues beneath a resected cord have constant and rich vascularization. Moreover, fat grafting is extensively used in aesthetic and reconstructive plastic surgery, even with larger cannulas (4 mm) without compromising the viability of the fat grafted.

We believe it is important to point out the effects of fat injection based on the adopted surgical technique. Further experimental and clinical studies may demonstrate the physiological mechanisms involved that could explain our results.

Perhaps, surgical aggression associated with fat graft promoted more local inflammatory reaction. However, there are no histological elements in our study to prove this hypothesis.

We found that fat grafting did not confer benefits when compared with the control group when associated with open limited fasciotomy in the short term (1 year postoperatively). However, questions remain regarding the long-term results and if the stem cells exist in the fat graft could interfere with the recurrence of the disease in the future.

One of the limitations of our study is the short follow-up time of 1 year for the evaluation of postoperative recurrence. For a better understanding of the outcomes of this technique, a longer follow-up period would be necessary.

\section{CONCLUSION}

The use of the fat graft associated with open limited fasciotomy in the treatment of DD promoted worse results when compared with conventional open limited fasciotomy in a short-term study regarding functional results and complications. Longer follow-up is required to evaluate the fat graft effect on recurrence of the disease.

\section{ACKNOWLEDGEMENTS}

The authors acknowledge Mr. Prof. Doctor Marcelo R. Rezende and Mr. Doctor Teng H. Wei, Head of the Hand and Microsurgery Division, respectively, of the Orthopedic and Traumatology Department, University of São Paulo, São Paulo, Brazil, for all support. The authors thanks all the participants involved in this study, including research patients.

AUTHORS' CONTRIBUTIONS: Each author contributed individually and significantly to the development of this article. MTCS: substantial contribution in the study conception or design, or acquisition, analysis or interpretation of data to the study and writing the article or critically reviewing its intellectual content; HAN: writing the article or critically reviewing its intellectual content; RBN: substantial contribution in the study conception or design, or acquisition, analysis or interpretation of data to the study; RMJ: approval of the final version of the manuscript to be submitted for publication; MRR: approval of the final version of the manuscript to be submitted for publication; THW: approval of the final version of the manuscript to be submitted for publication.

\section{REFERENCES}

1. Hurst LH. Dupuytren's contracture. In: Wolf FW, Hotchkiss RN, Pederson WC, Kozin SH, Cohen MS, editors. Green's operative hand surgery. Philadelphia: Elsevier; 2010. p. 141-58.

2. Hurst LC, Badalamente MA, Hentz VR, Hotchkiss RN, Kaplan FT, Meals RA, et al. Injectable collagenase clostridium histolyticum for Dupuytren's contracture. N Engl J Med. 2009;361(10):968-79.

3. Tubiana R. Evaluation of deformities in Dupuytren's disease. Ann Chir Main 1986;5(1):5-11

4. van Rijssen AL, Gerbrandy FS, Ter Linden H, Klip H, Werker PM. A comparison of the direct outcomes of percutaneous needle fasciotomy and limited fasciectomy for Dupuytren's disease: a 6-week follow-up study. J Hand Surg Am. 2006;31(5):717-25.

5. van Rijssen AL, Werker PM. Percutaneous needle fasciotomy in Dupuytren's disease. J Hand Surg Br. 2006;31(5):498-501.

6. Pu LL, Yoshimura K, Coleman SR. Future perspectives of fat grafting. Clin Plast Surg. 2015;42(3):389-94

7. Khouri RK, Smit JM, Cardoso E, Pallua N, Lantieri L, Mathijssen IM, et al. Percutaneous aponeurotomy and lipofilling: a regenerative alternative to flap reconstruction? Plast Reconstr Surg. 2013;132(5):1280-90.

8. Verhoekx JS, Mudera V, Walbeehm ET, Hovius SE. Adipose-derived stem cells inhibit the contractile myofibroblast in Dupuytren's disease. Plast Reconstr Surg. 2013;132(5):1139-48.

9. Hovius SE, Kan HJ, Smit X, Selles RW, Cardoso E, Khouri RK. Extensive percutaneous aponeurotomy and lipografting: a new treatment for Dupuytren disease. Plast Reconstr Surg. 2011;128(1):221-8.
10. Coleman SR. Long-term survival of fat transplants: controlled demonstrations. Aesthetic Plast Surg. 1995;19(5):421-5.

11. Coleman SR. Structural fat grafting: more than a permanent filler. Plast Reconstr Surg. 2006;118(3 Suppl):108S-20S.

12. Khouri RK Jr, Khouri RK. Current clinical applications of fat grafting. Plast Reconstr Surg. 2017;140(3):466e-86e.

13. Fernandes CH, Raduan Neto J, Meirelles LM, Pereira CN, Santos JBG, Faloppa F. Translation and cultural adaptation of the Brief Michigan Hand Questionnaire to Brazilian Portuguese language. Hand (N Y). 2014;9(3):370-4.

14. Harris PA, Taylor R, Thielke R, Payne J, Gonzalez N, Conde JG. Research electronic data capture (REDCap) - a metadata-driven methodology and workflow process for providing translational research informatics support. J Biomed Inform. 2009;42(2):377-81.

15. Hovius SE, Kan HJ, Verhoekx JS, Khouri RK. Percutaneous aponeurotomy and lipofilling (PALF): a regenerative approach to Dupuytren contracture. Clin Plast Surg. 2015;42(3):375-81.

16. Kan HJ, Selles RW, van Nieuwenhoven CA, Zhou C, Khouri RK, Hovius SE. Percutaneous aponeurotomy and lipofilling (PALF) versus limited fasciectomy in patients with primary Dupuytren's contracture: a prospective, randomized, controlled trial. Plast Reconstr Surg. 2016;137(6):1800-12.

17. Cheung K, Walley KC, Rozental TD. Management of complications of Dupuytren contracture. Hand Clin. 2015;31(2):345-54.

18. Harden RN, Bruehl S, Stanton-Hicks M, Wilson PR. Proposed new diagnostic criteria for complex regional pain syndrome. Pain Med. 2007;8(4):326-31. 
In the article entitled "RANDOMIZED CONTROLLED TRIAL OF LIMITED FASCIOTOMY WITH INJECTION OF ADIPOSE GRAFT FOR DUPUYTREN'S DISEASE" authored by Marina Tommasini C. Sambuy, Hugo A. Nakamoto, Raul Bolliger Neto, Rames Mattar Jr., Marcelo R. Rezende, Teng Hsiang Wei, published in Revista Acta Ortopédica Brasileira (ACTA) vol. 28 n 4, 2020 , pages 159 (except for lines 3 and 12 of the introduction), 160, 163, 164, DOI: http://dx.doi.org/10.1590/1413-785220202804233522, by request of the authors.

Where it reads: Fasciotomy

Read: Fasciectomy 